\title{
Evaluation of the antral pseudocysts and maxillary sinus septas by using cone-beam computed tomography
}

\author{
Mustafa Yalçın'1(D, Nihat Laçin² ${ }^{(1)}$ \\ ${ }^{1}$ Gaziantep University, Faculty of Dentistry, Department of Oral and Maxillofacial Surgery, Gaziantep, Turkey \\ 2 İzmir Katip Çelebi University, Faculty of Dentistry, Department of Oral and Maxillofacial Surgery, İzmir, Turkey
}

\section{Correspondence:}

\section{Dr. Mustafa YALÇIN}

Gaziantep University, Faculty of Dentistry, Department of Oral and Maxillofacial Surgery, Gaziantep, Turkey.

E-mail:myalcin.omfs@gmail.com

Received: 02 March 2020

Accepted: 04 August 2020

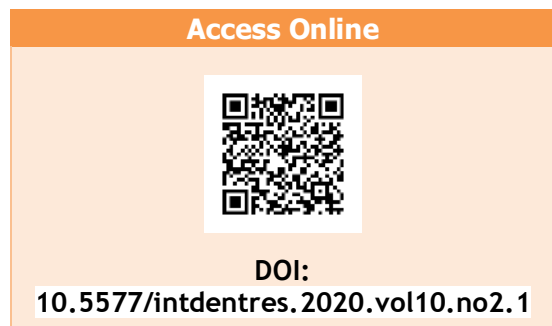

\section{Introduction}

Implant placement in maxilla ensures prosthetic rehabilitation of partial or completely edentulous patients. However, the quality and quantity of dentoalveolar bone are crucial to perform optimal dental implant surgery and prosthetic superstructure. The height and width of the dentoalveolar bone determine the diameter and length of the endosteal implant. In the posterior maxillary region, resorption of the dentoalveolar bone causes the challenge in dental implant surgery. To increase the height of the residual alveolar bone or insertion of the endosteal implant, various techniques were used such as sinus lifting procedures. Two main sinus lifting procedures which are transcrestal and lateral window techniques are used for implant placement and/or bone augmentation. Maxillary sinus might have some anatomic variations (maxillary sinus septa) and/or pathological entities such as antral pseudocysts (AP), polyps and odontogenic cysts. These anatomic or 
pathological entities may lead to complications during sinus lifting procedures. The presence of the maxillary sinus septas (MSS) and AP may lead to perforation of the Schneiderian membrane during sinus floor elevation $(1,2,3)$.

MSS were first defined by the anatomist Arthur S. Underwood and also called as Underwood's septa (4). MSS are described as a thin cortical bone that subdivided the sinus into the two or more chambers $(5,6)$. Several hypotheses had been forwarded about the etiology of MSS. Krenmair et al. subdivided MSS into primary and secondary, with the primary septa occurring during the growth of the maxilla and secondary septa develop from the irregular pneumatization of the sinus floor following tooth loss (7).

AP are radiopaque, dome-shaped entities without lined by true epithelium and formed by serous exudate accumulation (8). These entities are asymptomatic and incidentally detected in the radiological examination especially $C B C T$. Although the etiology of AP remains controversial, it has been assumed that AP might be associated with odontogenic infection, upper respiratory infection, trauma, temperature, smoking, humidity, allergic reaction (912).

CBCT, panoramic radiography and computed tomography $(C T)$ were used to examine the anatomical structures, pathological entities in the maxillary sinus. $\mathrm{CBCT}$ ensures following in radiological examination; i) 3-dimensional examination with lower radiation dose than conventional $\mathrm{CT}$, ii) prevents the superimposition of anatomic structures and pathological entities, iii) provides accurate, detailed visualization and radiological examination (13-20). The purpose of this study was to evaluate the prevalence of the AP, MSS and relationship between AP and MSS in the maxillary sinus by using CBCT images.

\section{Materials and Methods}

\section{Study sample}

In this retrospective study, 700 cone-beam computed tomography (CBCT) results were examined and, after the inclusion criteria were applied, a total of 466 CBCT were included. The CBCT scans had been acquired for diagnostic purposes of dentoalveolar, maxillofacial surgery and orthodontic treatment. Informed consent had been obtained from all patients before exposure. Exclusion criteria were; comprised of inadequate scan quality, impacted teeth in the maxillary sinus, chronic infection or cyst and tumorassociated with the maxillary sinus, previous maxillofacial trauma or maxillary sinus surgery, dental implant placement, bone augmentation. All images were retrieved from the archives of the Faculty of Dentistry, İzmir Katip Çelebi University, and related to work performed between January 2014 and July 2018. This study was approved by Izmir Katip Çelebi University, Ethics Committee (Year:2019, No:529) following the Helsinki Declaration 1975, as revised in 2000.

\section{CBCT image acquisition, evaluation of the antral pseudocyst and maxillary sinus septas}

Images were obtained with a CBCT device (NewTom 5G CBCT machine, QR s.r.l., Verona, Italy). The exposure parameters were adjusted at $110 \mathrm{kVp}, 1$ $20 \mathrm{~mA}$, with $15 \times 12 \mathrm{~cm}$ field of view and resolution mode (voxel size $0.2 \mathrm{~mm}$ ). The presence of maxillary sinus septas (MSS) and antral pseudocysts(AP) were detected on NNT station (QR srl, Verona, Italy) using the "zoom" tool and manipulation of brightness and contrast on a computer monitor (The RadiForce MX270W features a 27 -inch large screen size and a 2560 x 1440 high-resolution) under dim lighting conditions. AP were defined as unilacunar, dome-shaped, radiopaque lesion without any bone resorption on the wall of the maxillary sinus especially floor of the sinus. In the detection of MSS, a line was drawn at the base of the septa and its height was measured using a line extending from this base to the most coronal part of the septa (21). When the vertical dimension of the MSS was over $2.5 \mathrm{~mm}$, the MSS were admitted to the present study (21). AP and MSS were confirmed at the coronal, axial and sagittal section of CBCT images. AP and MSS were analyzed according to gender and localization (right or left maxillary sinuses), (Fig. 1 and 2).
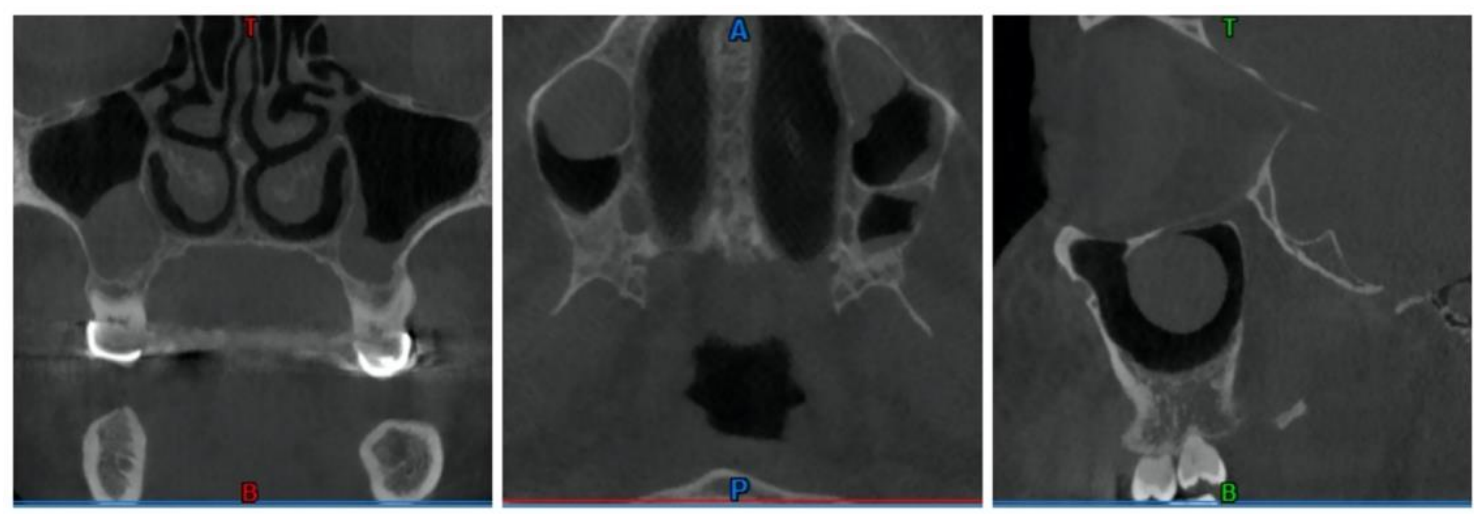

Figure 1. CBCT images of antral pseudocysts (AP). Coronal, axial and sagittal sections of AP. 

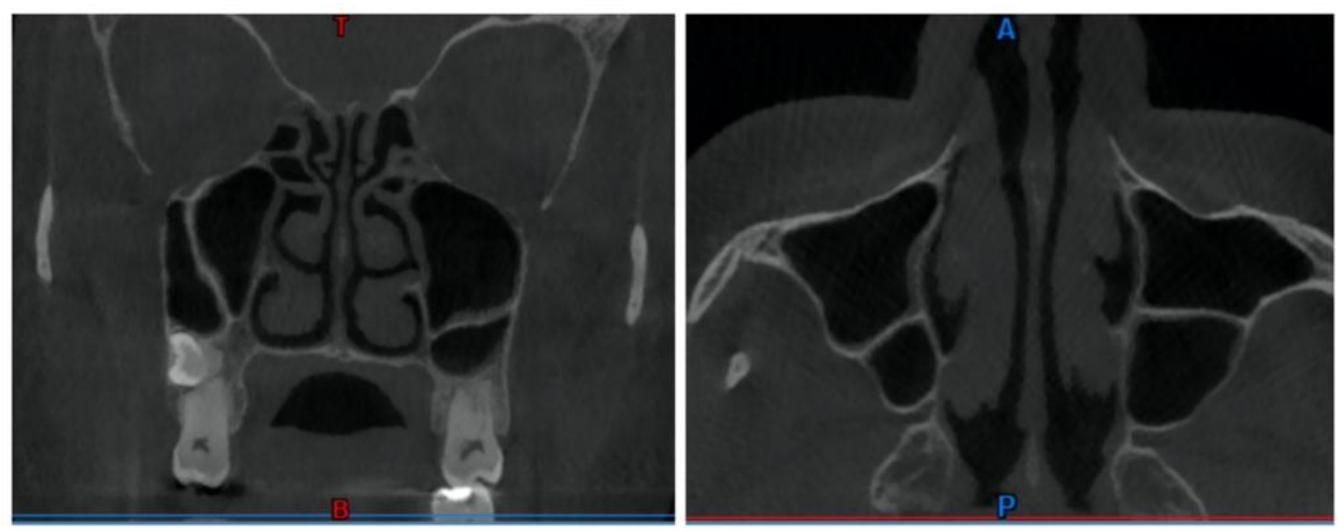

Figure 2. CBCT images of maxillary sinus septas (MSS). Coronal and axial sections of MSS.

\section{Statistical Analysis}

Descriptive statistic parameters were presented as frequency, percentage (\%) and mean \pm standard deviation (mean \pm SD). The recorded data were statistically analyzed using the Pearson Chi-square test (x2) to compare the prevalence of AP and MSS between genders and sides. Spearman's correlation tests were used to analyze the relationship between AP and MSS (SPSS Inc, Chicago, IL, USA).

\section{Results}

The study included 466 patients ( 237 men and 229 women) with a mean age of 40.53 years. The mean age was 41.70 years in men and 39.32 years in women. When the prevalence of the AP in men and women was analyzed, 123 out of 237 patients in men $(51.90 \%)$ and 75 out of 229 patients in women(32.75\%) had AP in the right and left maxillary sinuses. One hundred-ninety eight out of $466(42.49 \%)$ patients had AP in the right and left maxillary sinuses (Table 1). There was a significant difference in the prevalence of AP between men and women $(p \leq 0.001)$. The prevalence of AP was higher in men than in women. There was a significant difference in the prevalence of MSS between men and women $(p \leq 0.001)$. Twenty-eight out of 237 patients in men (11.81\%) and 35 out of 229 patients in women $(15.28 \%)$ had MSS in the right and left maxillary sinuses (Table 2). The prevalence of the MSS in the right and left maxillary sinuses was $13.52 \%$ (63 of 466 patients), (Table 2). We did not determine a significant relationship between AP and MSS in the right and left maxillary sinuses (Table 3 ). There was a significant difference between right and left $A P$ in the sinus $(p \leq 0.001)$, (Table 3). Furthermore, there was a significant difference between right and left MSS, $(p \leq 0.001)$, (Table 3).

Table 1. Distribution of the AP according to gender and localization.

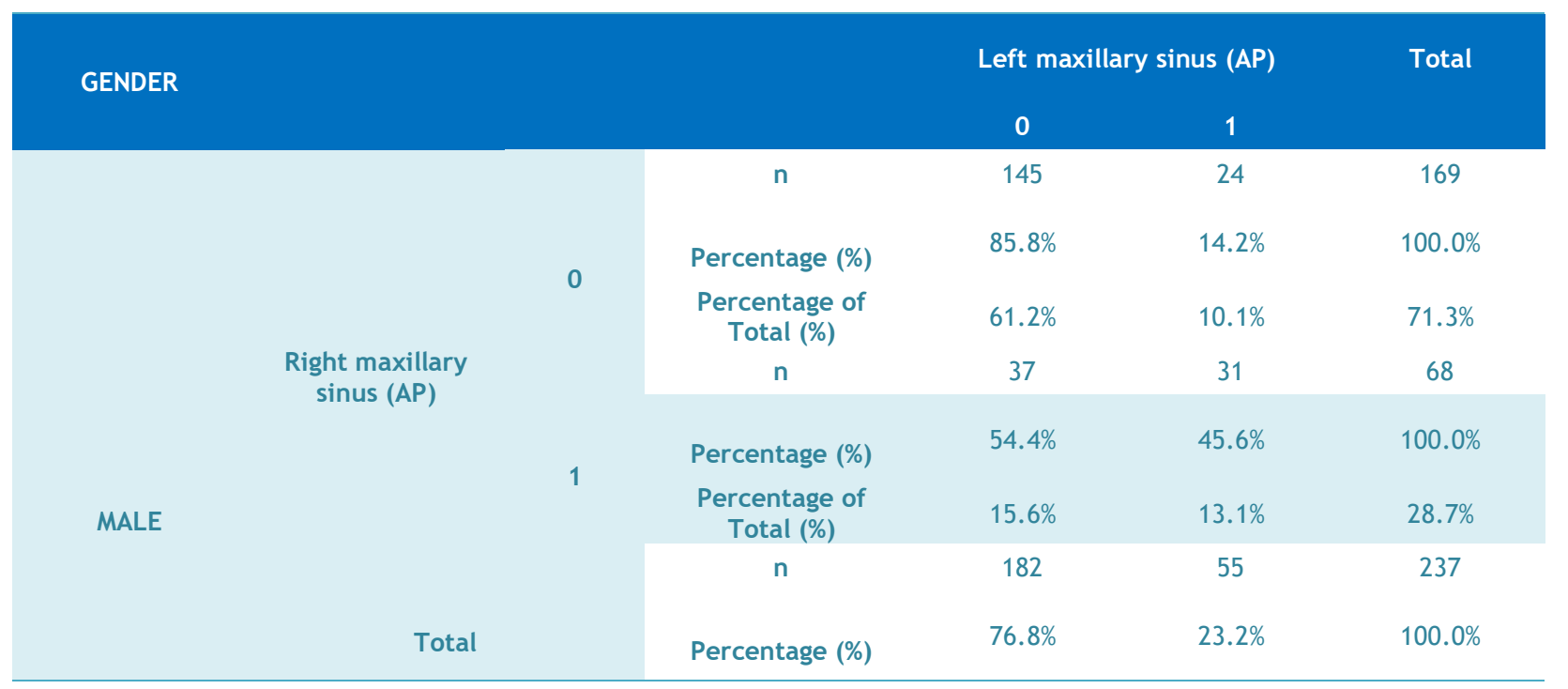




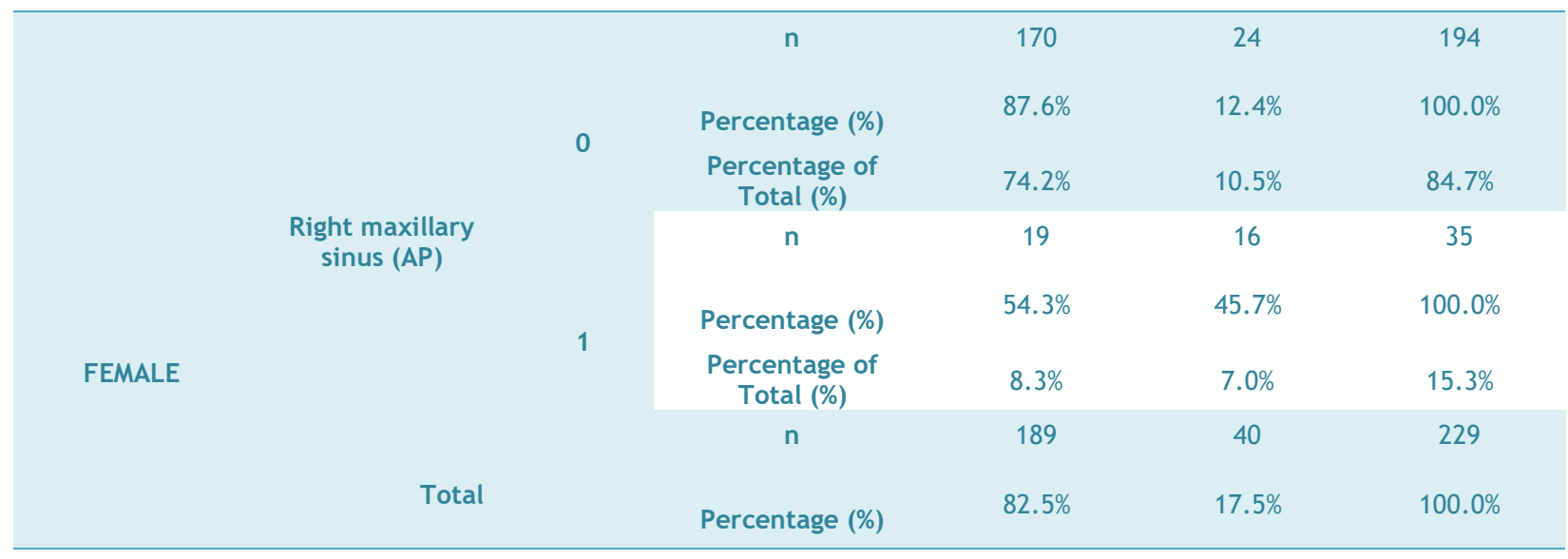

$(\mathrm{AP}=$ Antral pseudocyst, $0=$ absence of $\mathrm{AP}, 1=$ presence of $\mathrm{AP})$

Table 2. Distribution of the MSS according to gender and localization.

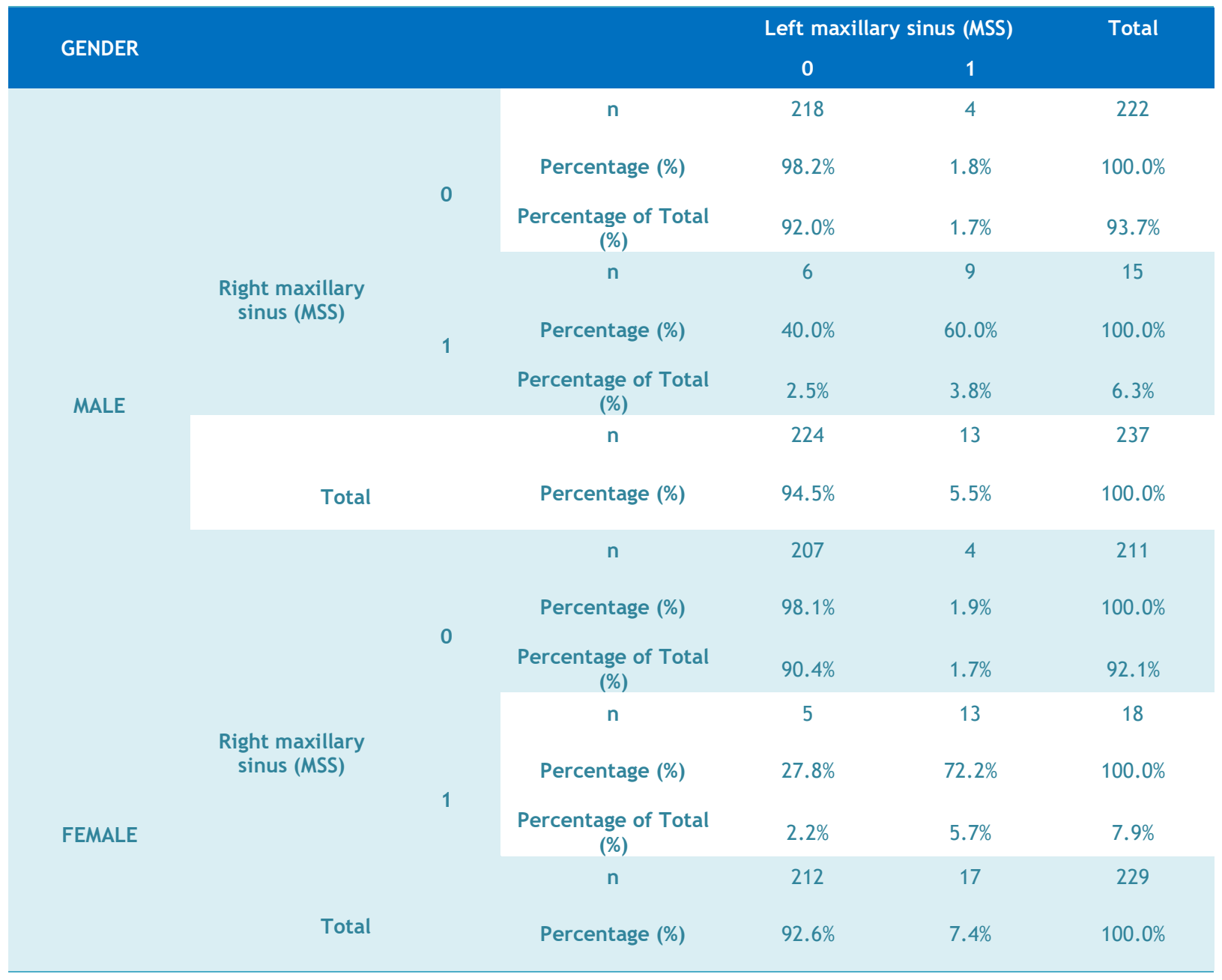

(MSS= Maxillary sinus septas, $0=$ absence of MSS, $1=$ presence of MSS) 
Table 3. Spearman's correlation test was performed to analyze the correlation between AP and MSS.

\begin{tabular}{|c|c|c|c|c|c|c|}
\hline Spearman's rho & & & Right AP & Left AP & Right MSS & Left MSS \\
\hline & \multirow[t]{2}{*}{ Right AP } & $\begin{array}{c}\mathrm{R} \text { (Correlation } \\
\text { Coefficient) }\end{array}$ & 1.000 & $.334(* *)$ & -.026 & -.013 \\
\hline & & $\begin{array}{l}\mathrm{p} \\
\mathrm{n}\end{array}$ & 466 & $\begin{array}{c}0,000 \\
466\end{array}$ & $\begin{array}{l}.574 \\
466\end{array}$ & $\begin{array}{l}.775 \\
466\end{array}$ \\
\hline & \multirow[t]{2}{*}{ Left AP } & $\begin{array}{c}\mathrm{R} \text { (Correlation } \\
\text { Coefficient) }\end{array}$ & $.334(* *)$ & 1.000 & .068 & .084 \\
\hline & & $\begin{array}{l}\mathrm{p} \\
\mathrm{n}\end{array}$ & $\begin{array}{c}0.000 \\
466\end{array}$ & 466 & $\begin{array}{l}.143 \\
466\end{array}$ & $\begin{array}{l}.069 \\
466\end{array}$ \\
\hline & \multirow[t]{2}{*}{ Right MSS } & $\begin{array}{c}\mathrm{R} \text { (Correlation } \\
\text { Coefficient) }\end{array}$ & -.026 & .068 & 1.000 & $.677\left(^{* *}\right)$ \\
\hline & & $\begin{array}{l}\mathrm{p} \\
\mathrm{n}\end{array}$ & $\begin{array}{l}.574 \\
466\end{array}$ & $\begin{array}{l}.143 \\
466\end{array}$ & $\dot{466}$ & $\begin{array}{c}0.000 \\
466\end{array}$ \\
\hline & \multirow[t]{2}{*}{ Left MSS } & $\begin{array}{c}\mathrm{R} \text { (Correlation } \\
\text { Coefficient) }\end{array}$ & -.013 & .084 & $.677\left(^{* *}\right)$ & 1.000 \\
\hline & & $\begin{array}{l}\mathrm{p} \\
\mathrm{n}\end{array}$ & $\begin{array}{l}.775 \\
466\end{array}$ & $\begin{array}{l}.069 \\
466\end{array}$ & $\begin{array}{c}0.000 \\
466\end{array}$ & $\dot{466}$ \\
\hline
\end{tabular}

** Correlation is significant at the 0.01 level (2-tailed). (AP= Antral pseudocysts, MSS= Maxillary sinus septas)

\section{Discussion}

The maxillary posterior region might have some challenges during implant surgery, especially in sinus lifting procedures. The presence of the AP, antral polyps, mucous retention cyst, and odontogenic infections may affect the procedures of sinus lifting via a lateral window or transcrestal techniques. Moreover, anatomic variations of the maxillary sinus such as localization of the posterior superior alveolar artery, thickness of the maxillary sinus lateral wall, volume of the sinus, quantity of the residual dentoalveolar bone and MSS are another substantial points for sinus lifting procedures, success of the augmentation techniques and dental implant placement in the maxillary posterior region associated with the maxillary sinus. Because of these reasons, evaluation of maxillary sinus prior to surgical intervention is essential in order to prevent the Scheneiderian membrane perforation and obtain optimal outcomes postoperatively. In the present study, we examine the prevalence of the MSS and $A P$ in the sinus. And also, the relationship between the MSS and AP was evaluated by using CBCT.

Although some authors supposed that the presence of AP was not a contraindication in sinus lifting procedures with a lateral window or transcrestal approaches ( 22), AP might make difficulties in sinus lifting, bone augmentation or implant placement procedures. In the presence of AP, there is a high-risk perforation of the Scheneiderian membrane in the sinus lifting $(23,24)$. This perforation may prolong the duration of surgery and cause the failure of the bone graft or implant loss especially if there is an infection in the maxillary sinus $(23,24)$. Proussaefs et al. stated that implant survival rates were higher in nonperforated maxillary sinus membrane than in perforated sinus membrane (25). In the present study, one hundred-ninety eight out of 466 (42.49\%) patients had AP. The prevalence of AP was higher in men than in women (Table 1).

Several studies were reported associated with the prevalence of the MSS. Dentulous and edentulous patients might have a different prevalence of MSS. Hungerbühler et al. stated that edentulous patients had a higher prevalence of MSS partially and fully dentate patients (26). Laçin et al. reported that MSS was detected $40.28 \%$ of patients in their study (20). Bornstein et al. stated that $67 \%$ of 212 patients and $57 \%$ of 294 maxillary sinuses included MSS (27). In the previous studies associated with the prevalence of MSS, Dobele et al. (28), Lana et al. (29), Jang et al.(30) reported the percentage of MSS was $20.6 \%, 44.4 \%$, and $26 \%$, respectively. In the present study, the prevalence of the MSS was $13.52 \%$ (63 of 466 patients) and this percentage was lower than other studies (Table 2). This lower rate could be related to the limitations of the study. In our study, we excluded the patients from the study especially in cases dental implant placement related to the maxillary sinus, pathologies related to the sinus (except AP), surgical intervention such as bone augmentation associated with the sinus and trauma. Therefore, we supposed that the prevalence of MSS was lower than in other studies. When analysis of the AP and MSS was carried out, we did not determine any relationship between the presence of AP and MSS in the present study (Table 3). However, AP and MSS are risk factors for survival rates of graft materials and implants in sinus lifting procedures via a lateral window or transcrestal approaches.

\section{Conclusions}

Although there was no relationship between the presence AP and MSS, the prevalence of AP and MSS was $42.49 \%$ and $13.52 \%$, respectively and the prevalence of MSS was lower in our study than other studies. The presence of MSS, AP and other anatomic variations/pathologies should be taken into consideration and evaluated preoperatively by using CBCT to increase the success of the surgical intervention. 
Ethical Approval: Ethics committee approval was received for this study from İzmir Katip Çelebi University, Ethics Committee in accordance the World Medical Association Declaration of Helsinki, with the approval number: 2019/529.

Peer-review: Externally peer-reviewed.

Author Contributions: Conception - M.Y.; Design - M.Y., N.L.; Supervision - M.Y.; Materials - N.L.; Data Collection and/or Processing M.Y., N.L.; Analysis and/or Interpretation - N.L.; Literature Review M.Y., N.L.; Writer - M.Y., N.L.; Critical Review - M.Y.

Conflict of Interest: No conflict of interest was declared by the authors.

Financial Disclosure: The authors declared that this study has received no financial support.

\section{References}

1. Al-Dajani M. Incidence, risk factors, and complications of Schneiderian membrane perforation in sinus lift surgery: a meta-analysis. Implant Dent 2016;25:409-15. (Crossref)

2. Toscano NJ, Holtzclaw D, Rosen PS. The effect of piezoelectric use on open sinus lift perforation: a retrospective evaluation of 56 consecutively treated cases from private practices. J Periodontol 2010;81:167-71. (Crossref)

3. Becker ST, Terheyden H, Steinriede A, Behrens E, Springer I, Wiltfang J. Prospective observation of 41 perforations of the Schneiderian membrane during sinus floor elevation. Clin Oral Implants Res 2008;19:1285-9. (Crossref)

4. Underwood AS. An inquiry into the anatomy and pathology of the maxillary sinus. J Anat Physiol 1910;44(Pt 4):354-69.

5. Rancitelli D, Borgonovo AE, Cicciu M, Re D, Rizza F, Frigo AC, Maiorana C. Maxillary sinus septa and anatomic correlation with the Schneiderian membrane. J Craniofac Surg 2015;26:1394-8. (Crossref)

6. Maestre-Ferrin L, Galan-Gil S, Rubio-Serrano M, PenarrochaDiago M, Penarrocha-Oltra D. Maxillary sinus septa: a systematic review. Med Oral Patol Oral Cir Bucal 2010;15: e3836. (Crossref)

7. Krennmair G, Ulm GW, Lugmayr H, Solar P. The incidence, location, and height of maxillary sinus septa in the edentulous and dentate maxilla. J Oral Maxillofac Surg 1999;57:667-671. (Crossref)

8. Rodrigues CD, de Arruda JAA, Silva LB, dos Santos Guimaraes C, Sobra APV, da Silveira MMF, Estrela C. Antral pseudocysts of the maxillary sinus: relationship between radiographic and clinical features. Journal of Oral Diagnosis, 2017;2.1: 1-7. (Crossref)

9. Carter LC, Calamel A, Haller A, Aguirre A. Seasonal variation in maxillary antral pseudocysts in a general clinic population. Dentomaxillofac Radiol. 1998 Jan;27(1):22-4. (Crossref)

10. Mafee MF, Valvassori GE, Becker M. Imaging of the Head and Neck. New York, Stuttgart, Thieme, 2005:406. (Crossref)

11. Nunes CA, Guedes OA, Alencar AH, Peters OA, Estrela CR, Estrela C. Evaluation of Periapical Lesions and Their Association with Maxillary Sinus Abnormalities on Cone-beam Computed Tomographic Images. J Endod. 2016 Jan;42(1):42-6. (Crossref)

12. Casamassimo PS, Lilly GE. Mucosal cysts of the maxillary sinus: a clinical and radiographic study. Oral Surg Oral Med Oral Pathol.1980;50:282-6. (Crossref)
13. Cangul S, Adiguzel O. Cone-Beam Three-Dimensional Dental Volumetric Tomography in Dental Practice. Int Dent Res 2017;7:62-70. (Crossref)

14. Aktuna Belgin $C$, Adiguzel $O$, Bud $M$, Colak M, Akkus Z. Mandibular Buccal Bone Thickness In Southeastern Anatolian People: A Cone-Beam Computed Tomography Study. Int Dent Res 2017;7:6-12. (Crossref)

15. Laçin N, Aytuğar E, Veli i. Cone-beam computed tomography evaluation of bifid mandibular canal. Int Dent Res 2018;8(2):7883. (Crossref)

16. Laçin N, Tatar B, Veli I, Adıgüzel A. Evaluation of medial lingual foramen with cone-beam computed tomography in a Turkish adult population. Int Dent Res 2018;8(3):139-43. (Crossref)

17. Falakaloglu $S$, Veis $A$. Determining the size of the mental foramen: A cone-beam computed tomography study. Int Dent Res 2017;7:20-25. (Crossref)

18. Açıklar Kavas A, Tümen EC. Volumetric pulp chambers measurements in mandibular and maxillary permanent first molar using cone-beam computed tomography by age and gender. Int Dent Res 2019;9(1):30-40. (Crossref)

19. Adiguzel O, Aktuna Belgin C, Falakaloglu S, Cangul S, Akkus S. Maxillary Cortical Bone Thickness in a South-Eastern Anatolian Population: A Cone-Beam Computed Tomography Study. Med Sci Monit 2017;23:5812-7. (Crossref)

20. Laçin N, İol BS. Evaluation of septas in maxillary sinus with cone-beam computed tomography. International Dental Research, 2019;9(2):41-45. (Crossref)

21. Lee WJ, Lee SJ, Kim HS. Analysis of location and prevalence of maxillary sinus septa. J Periodontal Implant Sci. 2010;40(2):5660. doi: $10.5051 /$ jpis.2010.40.2.56. (Crossref)

22. Kara MI, Kirmali $\mathrm{O}$, Ay S. Clinical evaluation of lateral and osteotome techniques for sinus floor elevation in the presence of an antral pseudocyst. Int J Oral Maxillofac Implants. 2012;27(5):1205-10.

23. Shin HI, Sohn DS. A method of sealing perforated sinus membrane and histologic finding of bone substitutes: A case report. Implant Dent. 2005;14:328-333. (Crossref)

24. Maksoud MA. Complications after maxillary sinus augmentation: A case report. Implant Dent. 2001;10:168-171. (Crossref)

25. Proussaefs P, Lozada J, Kim J, et al. Repair of the perforated sinus membrane with a resorbable collagen membrane: $A$ human study. Int J Oral Maxillofac Implants. 2004;19:413-420.

26. Hungerbühler A, Rostetter $C$, Lübbers HT, Rücker $M$, Stadlinger B. Anatomical characteristics of maxillary sinus septa visualized by cone beam computed tomography. Int J Oral Maxillofac Surg. 2019;48(3):382-387. (Crossref)

27. Bornstein MM, Seiffert C, Maestre-Ferrin L, Fodich I, Jacobs R, Buser D, von Arx T. An analysis of frequency, morphology, and locations of maxillary sinus septa using cone beam computed tomography. Int J Oral Maxillofac Implants 2016;31:280-7. (Crossref)

28. Dobele I, Kise L, Apse P, Kragis G, Bigestans A. Radiographic assessment of findings in the maxillary sinus using cone-beam computed tomography. Stomatologija 2013;15(4):119-122.

29. Lana JP, Carneiro PM, Machado Vde C, de Souza PE, Manzi FR, Horta MC. Anatomic variations and lesions of the maxillary sinus detected in cone beam computed tomography for dental implants. Clin Oral Implants Res 2012;23(12):1398-1403. (Crossref)

30. Jang SY, Chung K, Jung S, Park HJ, Oh HK, Kook MS. Comparative study of the sinus septa between dentulous and edentulous patients by cone beam computed tomography. Implant Dent 2014;23(4):477-481. (Crossref) 